\section{Adenoid cystic carcinoma of the left main bronchus mimicking MacLeod's syndrome}

\author{
C L Wright, M Gandhi, C A Mitchell
}

\begin{abstract}
A 15 year old girl who was labelled as having MacLeod's syndrome on the basis of a chest radiograph was subsequently, at the age of 23 years, found to have an adenoid cystic carcinoma obstructing the left main bronchus. This case emphasises the need to exclude a central lesion in cases of unilateral hyperlucent lung.

(Thorax 1996;51:451-452)
\end{abstract}

Keywords: adenoid cystic carcinoma, MacLeod's syndrome, bronchoscopy.

\section{Case report}

A 23 year old woman presented with left sided pleuritic pain and haemoptysis. Physical examination revealed reduced expansion and markedly reduced breath sounds over the left lung.

She had previously had a chest radiograph at the age of 15 years for recurrent upper respiratory tract infections. This had shown a hyperlucent left lung with reduced vascular markings and a small hilum. She was thought to have MacLeod's syndrome and no further evaluation was undertaken at that time. Over the intervening years she suffered mild exertional dyspnoea and intermittent left chest tightness.

Her chest radiograph on this admission (fig 1) was unchanged in appearance. An isotopic lung scan showed absent ventilation and perfusion to the left lung. Bronchoscopic

\section{Department of Respiratory Medicine C L Wright C A Mitchell}

\section{Department of} Diagnostic Radiology $M$ Gandhi

Princess Alexandra Hospital, Brisbane, Australia 4102

Correspondence to: Dr C L Wright.

Received 14 September 1994

Accepted for publication 2 February 1995

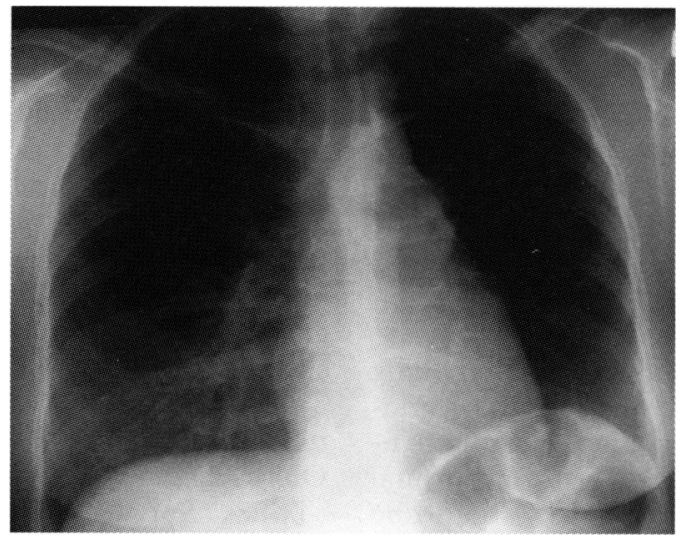

Figure 1 Chest radiograph at presentation showing a hypertranslucent left lung with diminished vascular markings and a small left hilum. examination revealed a vascular tumour occluding the left main bronchus, and adenoid cystic carcinoma was seen on biopsy specimens. A computed tomographic scan (fig 2) showed a $3 \mathrm{~cm}$ mass compressing the left main bronchus.

The patient subsequently underwent a left pneumonectomy. Microscopic examination showed an adenoid cystic carcinoma with poorly differentiated solid areas. The bronchial resection margin was involved with tumour and two of six mediastinal lymph nodes contained carcinoma. Two weeks postoperatively the patient presented with back pain and was found to have vertebral and pelvic bony metastases.

\section{Discussion}

MacLeod's or Swyer-James' syndrome is a rare condition characterised by a unilateral radiographically hyperlucent lung. It is thought to be related to an infective obliterative bronchiolitis in infancy and is usually asymptomatic. ${ }^{12}$ Pulmonary oligaemia and a diminutive hilum are features of the condition which may be explained by vasoconstriction induced by alveolar hypoxia in the affected lung.

Incompletely obstructing lesions in central bronchi may also result in alveolar hypoxia and decreased perfusion without distal atelectasis, thereby mimicking MacLeod's syndrome. ${ }^{3}$ As both conditions may show air trapping it would be difficult to differentiate between the two with inspiratory/expiratory radiographs. Bronchoscopy is therefore essential to exclude an endobronchial lesion.

Adenoid cystic carcinoma accounts for approximately $0 \cdot 2 \%$ of primary lung cancers. ${ }^{4}$ Typically a slow growing tumour, it is usually associated with prolonged survival. However,
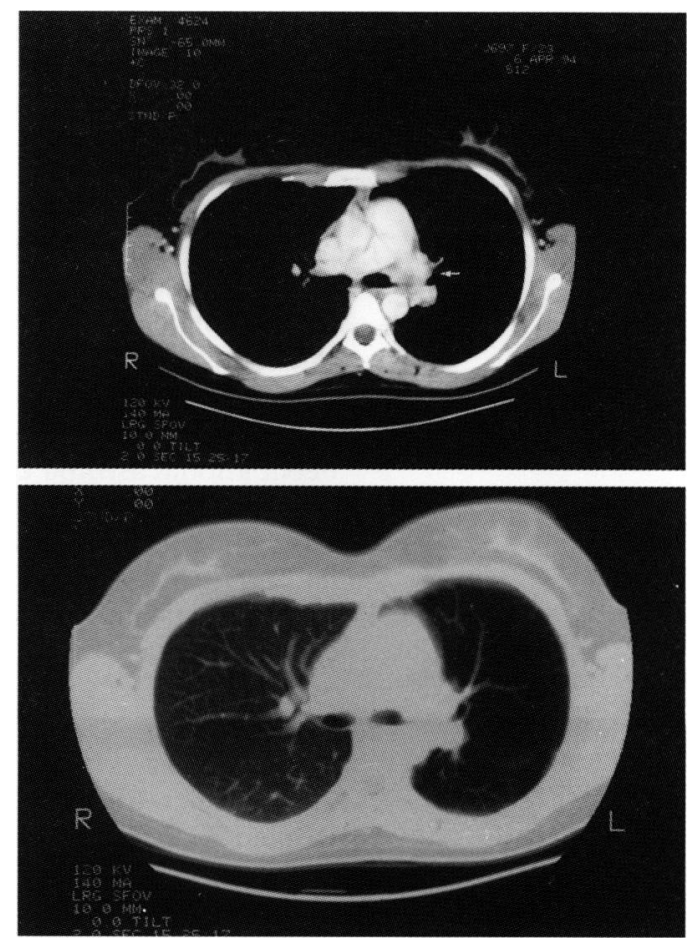

Figure 2 Computed tomographic scan with intravenous contrast showing a $3 \mathrm{~cm}$ mass narrowing the left main bronchus (arrow). The left pulmonary artery is small with decreased vascular markings on the lung windows. 
in the presence of distant metastases survival is usually less than two years. ${ }^{56}$ This is one of the youngest cases of adenoid cystic carcinoma reported in the literature.

The pneumonectomy specimen showed no histopathological features of MacLeod's syndrome. The radiological features discovered at the age of 15 years are therefore almost certainly a result of central airway narrowing due to the adenoid cystic carcinoma which was ultimately found eight years later.

Lack of radiological change over several years cannot therefore exclude the possibility of a malignant endobronchial lesion causing a unilateral hyperlucent lung.

1 Swyer P, James G. A case of unilateral pulmonary emphysema. Thorax 1953;8:133-6.

2 MacLeod WM. Abnormal transradiancy of one lung. Thorax 1954;9:147-53.

3 Fraser RG, Paré JAP. Diagnosis of diseases of the chest. 2nd edn. Philadelphia: W B Saunders, 1977:553-61.

4 Turnbull AD, Huvos AG, Goodner JT, Beattie EF Jr. The malignant potential of bronchial adenoma. Ann Thorac Surg 1972;14:453-62.

5 Moran CA, Suster S, Koss MN. Primary adenoid cystic carcinoma of the lung. A clinicopathologic and immunohistochemical study of 16 cases. Cancer 1994;73:1390-7.

6 Conlan AA, Payne WS, Woolner LB, Sanderson DR. Adenoid cystic carcinoma (cylindroma) and mucoepidermoid carcystic carcinoma (cylindroma) and mucoepidermoid carCardiovasc Surg 1978;76:369-77.
Department of Chest

Medicine, Mont-

Godinne Hospital,

Catholic University

of Louvain,

5530 Yvoir, Belgium

O Vandenplas

J-P Delwiche

Y Sibille

Correspondence to: Dr O Vandenplas.

Received 18 November 1994

Accepted for publication

16 January 1995

\section{Occupational asthma due to latex in a hospital administrative employee}

Olivier Vandenplas, Jean-Pierre Delwiche, Yves Sibille

\author{
Abstract \\ A case is described of occupational asthma \\ caused by indirect exposure to airborne \\ latex allergens in an administrative hos- \\ pital employee who never used latex \\ gloves. \\ (Thorax 1996;51:452-453)
}

Keywords: asthma, occupational diseases, latex.

There is convincing evidence that allergenic proteins from latex bind to cornstarch glove powder, ${ }^{1}$ become airborne, ${ }^{2}$ and have the potential to cause rhinitis and asthma. ${ }^{34}$ All cases of occupational asthma due to latex described so far have been in workers manufacturing ${ }^{5}$ or using ${ }^{346}$ latex gloves. We report a case of occupational asthma caused by latex in a medical secretary who had no direct contact with latex materials. This observation indicates that latex-induced asthma may result from purely indirect exposure to airborne latex in medical environments.

\section{Case report}

The subject was a 32 year old non-smoking women who experienced work-related rhinoconjunctivitis six months after starting employment as a medical secretary of a hospital emergency room in January 1988. About one year later she noticed chest tightness, wheezing, and coughing both at work and also at home after a work shift, during exercise, and when exposed to non-specific irritants. The symptoms never occurred at night and were easily relieved by an inhaled bronchodilator. Skin prick tests with common inhalant allergens gave negative results. In July 1993 asthma symptoms became noticeably less frequent. It was later noticed that around that time non-sterile latex examination gloves were replaced by vinyl gloves in the hospital. In December 1993 the subject developed contact urticaria when wearing household latex gloves. She denied having ever used cleaning gloves, medical gloves, or other latex materials including condoms before experiencing this urticarial rash. Although her office was completely separated from the emergency rooms, she occasionally had to walk through these rooms to carry medical files. However, she never stayed in the rooms for prolonged periods nor had direct contact with medical materials including gloves. She reported having had a caesarean section in 1982 and 1987 without allergic symptoms.

Skin tests using a commercial extract of latex (Stallergènes SA, Brussels, Belgium) elicited a $7 \mathrm{~mm}$ weal reaction. Total IgE concentration was normal $(59 \mathrm{IU} / \mathrm{ml})$ while a high level of specific IgE against latex $(10.3 \mathrm{IU} / \mathrm{ml}$, Pharmacia CAP system, Uppsala, Sweden) was detected. Spirometric tests showed a forced expiratory volume in one second $\left(\mathrm{FEV}_{1}\right)$ of 3.251 (93\% predicted value) and a $92 \%$ predicted ratio of $\mathrm{FEV}_{1}$ to forced vital capacity (FVC). The subject showed marked nonspecific bronchial hyperresponsiveness as the provocative concentration of histamine causing a $20 \%$ fall in $\mathrm{FEV}_{1}\left(\mathrm{PC}_{20}\right)$ was $0.08 \mathrm{mg} / \mathrm{ml}^{7}$ Monitoring of peak expiratory flow rates (PEFR) at work was not carried out as the clinical history suggested that exposure to latex in the work place was only minimal at the time of evaluation. It was therefore decided to perform inhalation challenge tests with latex gloves in the laboratory. ${ }^{346}$ On the first day the subject handled vinyl gloves for 60 minutes in a $5 \mathrm{~m}^{3}$ challenge room without eliciting significant changes in $\mathrm{FEV}_{1}$ or in PEFR (figure). On the next day she was exposed to latex gloves (Triflex Surgical Gloves, Baxter Healthcare Corporation, Valencia, CA) for progressively longer periods of time. She was asked to shake each pair of gloves for three minutes while 